\title{
A ESTRUTURA METAFÍSICA DO SER INCRIADO E DOS SERES CRIADOS NO DE TRINITATE DE SEVERINO BOÉCIO
}

\author{
Daniela Silveira \\ Gabinete de Filosofia Medieval do \\ Instituto de Filosofia da Universidade do Porto
}

Desde os seus primórdios, a religião cristã procurou adquirir uma dimensão de pensamento e linguagem que descodificasse a revelação e permitisse, por um lado, um entendimento racional dos dados dessa mesma revelação e, por outro lado, - exactamente a partir desse entendimento racional - a constituição de uma comunidade universal. Neste sentido, os primeiros séculos do cristianismo foram marcados pelo esforço de construção de esquemas conceptuais e pelo estabelecimento de terminologias que clarificassem e sistematizassem os aspectos fundamentais e doutrinais desta nova religião. E, neste esforço, deu-se uma abertura e um diálogo com a cultura e a filosofia da época, aceitando-se que a razão, enquanto revelação natural, podia e devia ser usada na e para a compreensão das verdades da fé. A filosofia, numa atitude que persistiria durante toda a medievalidade, passou a acompanhar a religião, munindo-a dos instrumentos (conceptuais) necessários à fundamentação das suas verdades.

Severino Boécio vive e desenvolve o seu pensamento numa época em que as actividades filosóficas e cristã são também vistas como contíguas. Os seus Opuscula Sacra, nos quais se inclui o De Trinitate, revelam um filósofo movido pela curiosidade e pela busca de sentido, preocupado com o aprofundamento das verdades de fé e com a necessidade de elaboração de uma linguagem precisa, rigorosa e clara.

A sua actividade intelectual pode mesmo ser considerada, como afirma J. Savian Filho, como «uma tentativa de concretização, no âmbito da fé cristã, daquele ideal do homem, típico da sabedoria antiga, que busca o pleno conhecimento da verdade, vendo-se impelido a investigar tam-

Philosophica, 34, Lisboa, 2009, pp. 183-195 
bém as verdades da fé, quando essas lhe caem diante dos olhos, entrando no seu horizonte de investigação racional» ${ }^{1}$.

Boécio posiciona-se, assim, tal como o prisioneiro que personifica no De Consolatione Philosophiae, como um sábio, alguém que vive segundo a razão e usa todas as potencialidades da alma, na busca da sapientia. Alcançar este saber total significa - tal como as letras Pi e Theta nas vestes da Mestre Filosofia -, por um lado, viver de uma forma virtuosa para que, num plano prático, possa alcançar a felicidade máxima e, por outro lado, ascender, no plano teórico desde as ciências naturais até à teologia. Esta última apresenta-se como o fim de toda a actividade especulativa do homem.

A teologia tal como é apresentada no De Trinitate, é a parte mais elevada do saber especulativo, cuja excelência do objecto exige a maior atenção e cuidado, para que quem a ela se dedique não se deixe (segundo Boécio) «desviar por imaginações»².

Ela tem como objecto a forma pura, i.e., a forma sem matéria. E esta forma que é objecto da teologia identifica-se com a substância divina, que é o próprio ser (ipsum esse) e a fonte do ser (ex qua esse est) ${ }^{3}$.

1 J. Savian Filho, «Introdução» in Escritos (Opuscula Sacra), trad., estudos introdutórios e notas de J. Savian Filho (Coleção Clássicos), Martins Fontes, São Paulo, 2005, p. 32.

2 Cfr. Boethius, The Theological Tractates. The Consolation of Philosophy. Trad. H.F. Stewart, E.K. Rand and S.J. Tester, Harvard University Press, Cambridge, 1990, p 8 (vd. n. 3). Esta foi a edição que serviu de referência para a realização deste trabalho. No sentido de simplificar as notas, optar-se-á por designar, a partir daqui, as passagens do tratado De Trinitate (que podemos encontrar nas pp. 2-30 da referida edição) por DT e por apresentá-las traduzidas para português. As referências à Consolação da Filosofia e aos Escritos teológicos basear-se-ão também nesta edição.

${ }^{3}$ Boécio apresenta neste tratado o esquema proposto no Comentário à Isagoge (e que encontra a sua inspiração na Metafísica de Aristóteles), segundo o qual as ciências especulativas, ainda que tenham o mesmo objecto primário - forma - encaram-no de maneiras diferentes e com métodos distintos. Assim, as ciências naturais, racionalmente (rationabiliter), tratam das formas que, em acto, não podem ser separadas da matéria, i.e., estudam as formas unidas à matéria e o movimento porque todo o corpo está sujeito ao movimento. As ciências matemáticas, demonstrativamente (disciplinaliter), consideram as formas dos corpos separadamente da matéria e do movimento. A teologia debruça-se intelectualmente (intelectualiter) sobre a forma sem matéria. Cfr. DT, p. 8-10: «Nam cum tres sint speculativae partes, naturalis, in

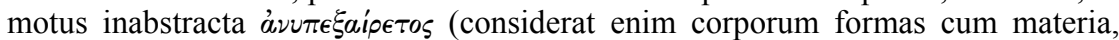
quae a corporibus actu separari non possunt, quae corpora in motu sunt ut cum terra deorsum ignis sursum fertur, habetque motum forma materiae coniuncta), mathematica, sine motu inabstracta (haec enim formas corporum speculatur sine materia ac per hoc sine motu, quae formae cum in materia sint, ab his separari non possunt), theologica, sine motu abstracta atque separabilis (nam dei substantia et materia et motu caret), in naturalibus igitur rationabiliter, in mathematicis disciplinaliter, in divinis intellectualiter versari oportebit neque diduci ad imaginationes, sed potius 
É a partir da classificação das ciências e, mais especificamente, do estabelecimento daquele que constitui o objecto da teologia que Boécio, no tratado de que nos ocupamos, descreve a estrutura metafísica dos seres e afirma a incomensurável diferença ontológica entre Deus, ser incriado e criador, e as criaturas.

O objectivo central no De Trinitate é o de responder à controvérsia gerada em torno da expressão «um da Trindade sofreu na carne», designadamente à possibilidade de, a partir do momento em que se diz «um da Trindade», as pessoas da Trindade poderem ser consideradas numeráveis e, consequentemente, diferenciadas ${ }^{4}$. $\mathrm{O}$ intuito de Boécio é, assim, o de demonstrar que Pai, Filho e Espírito Santo são um Deus (e não três deuses) porque na Trindade não há diferença.

O percurso realizado pelo autor nesta obra - que inicia com a demonstração da impossibilidade de aplicarmos os conceitos de diferença, pluralidade ou alteridade às pessoas divinas já que, segundo a doutrina aristotélica só se pode falar de diversidade no género, na espécie e no número (a aplicação dos dois primeiros não é evidentemente possível, restando assim verificar a possibilidade da última) - culmina na afirmação da diferença estrutural entre o Primeiro Ser e os seres que dele derivam.

Ora, como já dissemos, a teologia ocupa-se da substância divina, ou seja, ocupa-se de Deus.

A substância divina é, segundo o nosso autor, forma pura, i.e., forma sem matéria e, enquanto tal, é absolutamente simples. Dada a sua simplicidade e porque o que é absolutamente simples é uno (não há composição de elementos separados que depois são combinados), a substância divina é una e esta unidade e simplicidade fazem com que a sua forma coincida com a sua própria essência (est id quod est ${ }^{5}$ ). Ou seja, em Deus, a subs-

ipsam inspicere formam quae vere forma neque imago est et quae esse ipsum est et ex qua esse est.». Quanto ao esquema proposto no Comentário à Isagoge, cfr. Boethii, In Isagogen Porphirii Commenta, S. BRANDT (ed.), F. Tempsky/ G. Freyta, Vindobonae/Lipsiae, 1906, Liber I, c. 7, p. 7 ss.

$4 \mathrm{O}$ caminho trilhado pelo nosso autor não constitui uma novidade. Afinal esta é também a questão sobre a qual Agostinho se debruçou no seu De Trinitate. E terá sido no livro V do Hiponense que Boécio encontrou a inspiração para este seu tratado, e com o qual, como o próprio admite, procurará saber «se as sementes dos raciocínios provindos dos escritos do beato Agostinho produziram frutos» (DT, p. 4: «Vobis tamen etiam illud inspiciendum est, an ex beati Augustini scriptis semina rationum aliquos in nos venientia fructus extulerint».). A grande questão cristológica aqui subjacente é aquela que deu origem à controvérsia teopasquista, originada por um grupo de monges sírios, liderados por João Maxêncio, que consideravam que as resoluções de Calcedónia deviam ser complementadas com a fórmula de 'um da Trindade sofreu na carne'. Cfr. a propósito H. Chadwick, Boethius. The consolation of music, logic, theology and philosophy, p. 187-8.

${ }_{5}^{5}$ Id quod est deve ser aqui entendido no sentido exposto no axioma VII do De Hebdo- 
tância divina e a forma coincidem, são idênticas e, por isso, Deus é a sua própria essência ${ }^{6}$.

Deus é, de acordo com os axiomas III e IV do De Hebdomadibus ${ }^{7}$, o ser em si mesmo, puro e sem mistura com qualquer outra realidade diversa de si. Enquanto ser ou forma pura não pode ser substrato de acidentes porque a substância divina não tem acidentes e, neste sentido, não pode participar em alguma outra coisa (i.e., não pode possuir acidentes) porque é, afinal, apenas forma.

Ser e essência identificam-se, assim, no ser simples porque Deus não precisa de uma forma que o informe; Ele é já pura forma, não existindo qualquer diferença entre a sua essência e a sua forma.

A impossibilidade de distinguirmos em Deus o sujeito substancial da forma é também reiterada nas prosas 10 e 12 do De Consolatione - momento em que o autor onde o autor estabelece que Deus é o Bem ${ }^{8}$. Podemos afirmar que nesta obra, Boécio faz corresponder a forma essendi de Deus com a sua bondade porque a bondade identifica-se com Ele. Isto significa que não se pode dizer que Deus tenha recebido a forma do bem para passar a ser o bem perfeito mas sim que, tendo desde sempre o bem, Deus é simplesmente o bem perfeito porque possui em plenitude a bondade. Deste modo, de acordo com a afirmação de que a substância divina por ser forma sem matéria e por ser una, est id quod est, presente no De Trinitate, em Deus, a posse da bondade não pode ser considerada como algo extrínseco, que the advenha de fora, nem como uma "posse natural» porque estas implicariam a distinção entre o sujeito e a sua forma, algo inconcebível em Deus. E isto remete-nos obrigatoriamente para o axioma VII do De Hebdomadibus, onde escreve: «tudo o que é simples possui, numa unidade, o seu ser e isto que é» ${ }^{9}$. E a forma do ser divino é, de acordo com o metro 9 do livro III da Consolação, o sumo bem («insita summi forma boni») $)^{10}$.

A substância divina, o sumo bem é tal que não se dispersa nas coisas

madibus (Cfr. ed. citada, pp. 42) porque em Deus não há diferença entre esse e id quod est. Esta diferença só se aplica às coisas compostas. Parece-nos que aqui id quod est significa essência ou forma total e não a realidade existente (cfr. nota seguinte); assim, id quod est não é aqui usado como existência em antítese a essência.

${ }^{6}$ Cfr. DT, p. 10: «Sed divina substantia sine materia forma est atque ideo unum et est id quod est».

${ }^{7}$ Cfr. De Hebdomadibus, pp. 40-2: «III. Quod est participare aliquo potest, sed ipsum esse nullo modo aliquo participat. Fit enim participatio cum aliquid iam est; est autem aliquid, cum esse susceperit. IV. Id quod est habere aliquid praeterquam quod ipsum est potest; ipsum vero esse nihil aliud praeter se habet admixtum».

8 Cfr. De Consolatione Philosophiae, III, pr. 10, pp. 274-84.

${ }^{9}$ De Hebdomadibus, p. 42: «Omne simplex esse suum et id quod est unum habet».

10 Cfr. De Consolatione Philosophiae, III, m. 9, pp. 270-4. 
externas nem recebe em si nada exterior, nada tem de mistura para além de si mesmo; ela é totalmente ausente de matéria; nela não há possibilidade ou potencialidade de ser porque o ser está totalmente realizado e é actualmente perfeito, possui plenamente o próprio ser, é um todo unido sem qualquer distinção interna; est id quod est, é a sua forma e essência porque a forma ou essência nada tem de determinado e, como tal, coincide com o próprio ser ${ }^{11}$.

Em contraposição a esta absoluta simplicidade, unidade e pureza de forma, a criatura é composta. Toda a criatura é composta por matéria e pela forma que informa essa matéria e é essa composição. O ser da criatura não constitui uma unidade porque é composto pelas partes que formam essa composição. Toda a criatura deve o seu ser às partes que a constituem e 'é' essas partes em conjunção. A criatura é a realidade total, o resultado dessa conjunção. Vejamos o caso do homem: o todo é composto por alma e corpo; não é corpo ou alma separadamente. E, enquanto ser composto, enquanto forma e matéria, não pode ser a sua própria essência porque a forma é apenas uma parte da sua realidade concreta total $^{12}$.

Mas mesmo não sendo a sua própria essência, todas as coisas criadas devem o seu ser à forma e não à matéria. Para ser, toda a matéria que compõe as criaturas tem de ser informada porque se a forma é a fonte do ser, só pela forma a criatura é. A forma é, neste sentido, a condição de possibilidade do ser que se efectiva, que se torna realidade quando a matéria é informada. A forma é, então, a condição de determinação substancial dos seres.

Para ilustrar esta ideia, Boécio recorre ao exemplo de uma estátua de bronze. Uma estátua é uma combinação da matéria (bronze) e da semelhança com alguma figura que lhe é impressa. Nós avaliamos e consideramo-la como estátua a partir da forma que lhe foi gravada e não segundo a matéria de que é feita. Do mesmo modo, não consideramos o bronze como bronze segundo a matéria que a compõe (terra), mas segundo a figura do bronze. A própria terra é-o em consequência das suas formas, a secura e o peso ${ }^{13}$.

${ }^{11}$ Cfr. L. Obertello, Severino Boezio, Academia Ligure di Scienze e Lettere, Génova, 1974, p. 637 e p. 621.

12 Cfr. DT, p. 10: «Reliqua enim non sunt id quod sunt. Unum quodque enim habet esse suum ex his ex quibus est, id est ex partibus suis, et est hoc atque hoc, id est partes suae coniunctae, sed non hoc vel hoc singulariter, ut cum homo terrenus constet ex anima corporeque, corpus et anima est, non vel corpus vel anima in partem; igitur non est id quod est».

13 Idem: «Statua enim non secundum aes quod est materia, sed secundum formam qua in eo insignita est effigies animalis dicitur, ipsumque aes non secundum terram quod est eius materia, sed dicitur secundum aeris figuram. Terra quoque 
Assim, nas criaturas a forma é a fonte do seu ser e é a condição de passagem de mera potencialidade a acto - fazendo-se aqui ecoar a teoria potência-acto aristotélica - mas não coincide com o seu ser. No entanto, na qualidade de compostas, a forma do ser das criaturas não pode existir sem matéria - a matéria é, segundo L. Obertello, «a condição de possibilidade de determinação do composto que deriva da união da forma e da matéria ${ }^{14}-\mathrm{e}$, enquanto tal, estão sujeitas aos acidentes. E, exactamente por ser um ser material, a criatura pode ainda ser determinada por alguma outra coisa - os acidentes -, isto é, pode ser algo diferente daquilo que substancialmente é ${ }^{15}$.

Assim, - e respondendo directamente à questão que originou o tratado - enquanto pura forma, a substância divina não pode ser substrato de acidentes e, como tal, não pode ser numericamente diferenciada porque é o acidente que permite a distinção numérica dos indivíduos. Na substância divina não há diferença, não há a pluralidade introduzida pela diferença, nem a alteridade. Há uma unidade e identidade substancial ${ }^{16}$. O homem, por sua vez, enquanto ser composto, recebe os acidentes devido à matéria que lhe é subjacente e são estes acidentes que permitem diferenciá-los numericamente ${ }^{17}$.

Aqui reside o cerne da estrutura metafísica do ser incriado e do ser criado: é a diferença entre simplicidade e composição ou, de acordo com o Septenários ${ }^{18}$, a diferença entre a pura substancialidade e o ser compos-

ipsa non secundum ämoıv $\check{i} \lambda \eta \nu$ dicitur, sed secundum siccitatem gravitatemque quae sunt formae. Nihil igitur secundum materiam esse dicitur sed secundum propriam formam».

14 L. Obertello, Severino Boezio, p. 621.

15 Cfr. De Hebdomadibus, p. 40: «V. Diversum est tantum esse aliquid et esse aliquid in eo quod est; illic enim accidens hic substantia signicatur» (...) VI. Omne quod est participat eo quod esse ut sit; alio vero participat ut aliquid sit (...)».

16 Cfr. DT, p. 12. A unidade substancial das pessoas da Trindade não significa «uma completa indiferença entre elas» (cfr. DT, p. 16), mas esta questão só pode, na perspectiva de Boécio, ser esclarecida depois de se analisar a predicação em Deus. Como se mostrará no final deste tratado, as pessoas da Trindade diferem nas predicações relacionais que delas podem ser feitas, sem que, contudo, esta implique uma alteridade. Pai e Filho são termos que expressam uma relação. Se, ao falarmos da Trindade, não existisse qualquer outra distinção ou diferença para além da relação, a predicação não implicaria em si uma alteridade objectiva - porque não se trata de predicação essencial e, consequentemente, não alteraria, modificaria ou faria variar a essência -, ainda que pudesse produzir uma alteridade de pessoas $(\mathrm{Cfr}$. DT, p. 28-30).

17 Cfr. DT, p. 12: «Nam quod ceterae formae subiectae accidentibus sunt ut humanitas, non ita accidentia suscipit eo quod ipsa est, sed eo quod materia ei subiecta est; dum enim materia subiecta humanitati suscipit quodlibet accidens, ipsa hoc suscipere videtur humanitas».

18 Cfr. De Hebdomadibus, axiomas II a VII, pp. 40-2. 
to de substância e acidente ou ainda, se quisermos, a diferença entre o finito e o infinito postulada na Consolação ${ }^{19}$ : «Deus é forma pura e não pode ser sujeito ou existir na matéria»; [Nele não há lugar para o acidente]. A forma da criatura material, que é a fonte do seu ser, deriva da forma que existe à parte da matéria e «como a criatura é corpórea e composta de matéria e forma pode receber ulteriores determinações acidentais ${ }^{20}$.

Boécio, contudo, não se limita a distinguir Deus e as criaturas pela sua simplicidade e composição.

Mesmo dependendo da forma para ser, a forma que informa a matéria não se identifica com aquela de Deus. Por ser pura, por ser sem matéria e não poder ser substrato, a substância divina recebe correctamente a designação de forma porque é, afinal, a Forma. Em sentido estrito, a Forma está fora da matéria e não pode existir na matéria (ou deixaria de ser verdadeiramente forma), preservando deste modo a sua transcendência. A Forma é Deus, fonte e razão de ser de todas as criaturas.

Aquelas formas que dependem da Forma da forma (Deus) e que informam um corpo não devem ser designadas por forma mas sim por ima$\mathrm{gem}^{21}$. Estas são, no fundo, formas imanentes ou a forma material e, enquanto tais, são uma realidade diminuída, que imita e participa da verdadeira forma.

E esta diferença entre o ser divino e as criaturas que dele procedem acarreta também problemas de linguagem pois revela a insuficiência da linguagem humana quando se refere à essência divina e quando a tenta descrever, e anuncia também a incapacidade de encontrar conceitos que fixem e demarquem esta incomensurável dissemelhança.

Isto ocorre porque a essência divina, como coincide com o ser, é ela mesma, no sentido pleno e rigoroso, essência. A essência que «atribuímos às coisas sensíveis é apenas uma das categorias do nosso discurso sobre o ser (...) que é um modo da predicação ${ }^{22}$. Ou seja, a diferença ontológica entre Deus e as criaturas ainda que não implique que não se possa falar sobre Deus e que se construa um discurso com sentido sobre a divindade, deixa transparecer a impossibilidade de se falar directamente sobre a sua natureza, isto é, a impossibilidade de submeter a natureza divina à lógica das categorias.

Segundo o princípio plotiniano, que o nosso autor retoma, as catego-

19 Cfr. De Consolatione Philosophiae, II, pr. 7, pp. 218-20.

20 Cfr. L. Obertello, Severino Boezio, p. 622.

${ }^{21}$ Cfr. DT, p. 12: «Ex his enim formis quae praeter materiam sunt, istae formae venerunt quae sunt in materia et corpus efficiunt. Nam ceteras quae in corporibus sunt abutimur formas vocantes, dum imagines sint. Adsimulantur enim formis his quae non sunt in matéria constitutae».

22 Cfr. L. Obertello, Severino Boezio, p. 625. 
rias aplicam-se às coisas sensíveis e não às realidades supra-sensíveis ou Formas. A sua aplicação originária às coisas sensíveis não é problemáti$\mathrm{ca}^{23}$, mas o mesmo não se pode dizer quando falamos de Deus: «quando alguém as aplica à predicação de Deus, todas as coisas se alteram ${ }^{24}$. Isto acontece porque, para Boécio, na esteira dos neoplatónicos, a predicação constitui uma limitação e o «Uno não pode ser definido ou limitado pela predicação» ${ }^{25}$. O nosso autor, contudo, não levará, como veremos, este princípio aos seus limites - enveredando por uma teologia negativa -, já que permitirá toda a predicação substancial de Deus.

No entanto, não deixa de afirmar que Deus, na sua absoluta simplicidade, é mais do que substância, transcende a substância, é ultra-substância ${ }^{26}$. Mais do que substância, Deus é, de acordo com o tratado Contra Êutiques e Nestório, subsistência porque subsiste em absoluta independência sem precisar de nada. Substância em Deus, só pode ser dito se com isso quisermos expressar que Ele é princípio de tudo, de onde tudo procede, i.e., enquanto é o princípio sob todas as coisas (substare) às quais dá subsistência ${ }^{27}$. Deus é subsistência porque é o puro ser, «é a simplicidade anterior a todas as coisas, é o Uno, a causa de todas as substâncias porque toda a substância é composta» ${ }^{28}$. Deus é subsistência porque não precisa da propriedade substancial. A propriedade substancial é apenas própria daqueles que recebem a forma do seu ser para ser substância, mas Deus é já a Forma, não precisa de nada que o actualize porque é perfeita actualidade.

O homem, por sua vez, é composto e, da mesma forma que não é a sua própria essência, também não podemos afirmar correctamente que seja substância. O homem é um todo concreto, composto pela matéria e pela forma (ou melhor, pela imagem da forma) e como a sua forma é

23 Para Boécio, as categorias são instrumentos que devem ser cuidadosamente usados mesmo quando aplicados ao mundo ao discurso sobre o mundo sensível. É particularmente necessário distinguir entre aquelas categorias que mostram o que uma coisa é e as que revelam apenas as suas circunstâncias externas. Cfr. H. Chadwick, Boethius. The Consolation, p. 217. A ideia de que as categorias não providenciam um bom sistema de classificação quando aplicado às realidades supra-sensíveis está já presente em Plotino e é aceite quer por Proclo quer por Agostinho (Cfr. H. Chadwick, Boethius. The Consolation, p. 216).

24 DT, p. 16: «At haec cum quis in divinam verterit praedicationem, cuncta mutantur quae praedicari possunt».

25 Cfr. J. Marenbon, Boethius (Great Medieval Thinkers), Oxford University Press, Oxford, 2003, p. 83.

26 DT, p. 16-18: «Nam cum dicimus “deus”, substantiam quidem significare videmur, sed eam quae sit ultra substantiam.».

27 Cfr. CEN, III, particularmente, p. 91.

28 L. Obertello, Severino Boezio, p. 643. 
apenas uma parte do composto, esta não coincide com o seu ser. O homem existe apenas enquanto realidade total, no qual a forma da humanidade se uniu à matéria - e esta actua também como um substrato para acidentes.

O homem também é um subsistente mas nunca no sentido absoluto em que o afirmamos de Deus. Enquanto subsistente o homem apenas se torna substância por meio dos seus princípios diferenciadores e particularizantes. Ele apenas se torna substância quando recebe a forma do seu ser, passando a existir como sujeito dotado de uma forma determinada, i.e., como um existente ${ }^{29}$, capaz de receber ulteriores determinações.

Ora, isto é algo que em Deus não acontece e, por isso, há uma profunda diferença entre dizer-se a substância «homem» e a substância «Deus» porque os homens «non sunt id quod sunt», mas Deus «est id quod est» ${ }^{30}$.

Neste sentido, afirma Boécio, «como o homem não é simples e inteiramente homem, não é então substância. Mas Deus é simples e inteiramente o que é, é, por isso, simplesmente Deus (hoc ipsum Deus)» ${ }^{31}$.

Ou seja, enquanto o homem, o exemplo típico de uma substância na lógica de Aristóteles, existe como um todo concreto no qual a forma da humanidade surge unida à matéria e esta como substrato de acidentes, e não deve rigorosamente ser considerado uma substância, Deus na sua absoluta simplicidade pode correctamente ser designado de substância. Esta ideia, longe de entrar em confronto ou fragilizar a afirmação de Deus como ultra-substância, apenas a consolida. É que da mesma forma que dizemos que Deus é Forma e as formas nas criaturas não devem ser designadas por formas mas por imagens, também aqui o que se assevera é que, ao usar o mesmo termo para realidades tão diferentes, devemos ter consciência que estritamente falando só Deus é substância (pura substância) e, estabelecendo-se uma analogia, a substância no homem será apenas uma imagem daquela que o é verdadeiramente. Ou, se optarmos por

29 Podemos também considerar Deus como um existente porque enquanto uno e simples possui como algo único a existência e a essência, possuindo deste modo, quer a existência quer a essência num sentido mais pleno: é a sua própria existência e é a sua própria essência. Quanto aos argumentos sobre a absoluta necessidade da existência de Deus, cfr. De Consolatione, III, pr. 10

30 Cfr. DT, p. 10.

31 Cfr. DT, p. 20: «Sed haec praedicamenta talia sunt, ut in quo sint ipsum esse faciant quod dicitur, divise quidem in ceteris, in deo vero coniuncte atque copulate hoc modo: nam cum dicimis "substantia" (ut homo vel deus), ita dicitur quasi illud de quo praedicatur ipsum sit substantia, ut substantia homo vel deus. Sed distat, quoniam homo non integre ipsum homo est ac per hoc nec substantia; quod enim est, aliis debet quae non sunt homo. Deus vero hoc ipsum deus est; nihil enim aliud est nisi quod est, ac per hoc ipsum deus est». 
afirmar que o homem é uma substância, devemos fazê-lo desde que compreendamos a inferioridade ontológica deste conceito face à ultra-substancialidade divina ${ }^{32}$.

Assim, sendo Deus simples e inteiramente o que é, não há Nele lugar para os acidentes e por isso tudo o que Dele se possa dizer não poderá nunca ser predicado acidentalmente. Deus é mais propriamente sujeito de predicação substancial. Porém, nem tudo Dele se pode dizer porque há atributos que se lhe não aplicam.

Quando afirmamos que Deus é bom, a bondade não lhe é atribuída como uma característica acidental, mas substancial. Porque dizer que Deus é e é bom é a mesma coisa porque Deus é integre ipsum. Similarmente, dizer que Deus é grande é dizer que Deus é a grandeza e esta confunde-se com o seu ser. As categorias de qualidade e quantidade surgem, pois, como substanciais em Deus porque - como escreve Boécio «quando ditos de Deus, que não é de modo algum um substrato, é chamado predicação segundo a substância» ${ }^{33}$. Só a predicação substancial é possível em Deus e só se considera substancial aquilo que, segundo o Utrum Pater, pode ser predicado das três pessoas da Trindade ${ }^{34}$.

Deste modo, só a predicação intrínseca, aquela que segundo o autor, predica algo como sendo algo pode ser aplicada a Deus. As restantes categorias são extrínsecas e «apenas anexam[os] algo extrínseco à coisa», e são por isso, impróprias quando aplicadas a Deus (e subentende-se que também ao homem) - sobretudo quando comparadas às predicações segundo a substância, a qualidade e a quantidade - ou não devem sequer ser atribuídas à divindade ${ }^{35}$.

32 De acordo com S.A. Hipp, a distinção entre substância e subsistência constitui uma transformação ou amplificação da noção de substância aristotélica. Ao distinguir entre os dois conceitos, Boécio introduz a diferença entre os existentes sujeitos de acidentes e aqueles que não os são, instituindo deste modo a dissemelhença entre as ordens naturais e supra-naturais. Cfr. S.A. Hipp, "Person" in Christian Tradition and the Conception of Saint Albert the Great. A systematic study of its concepts as illuminated by the mysteries of the Trinity and the Incarnation, Beiträge zur Geschichte der Philosophie und Theologie des Mittelalters. Neue Folge, Band 57, Aschedorff Verlag, Münster, 2001, p. 109.

33 Cfr. DT, p. 24 (n. 35). Boécio apresenta ainda a ideia de justiça, estabelecendo também aqui a distinção entre ser justo em Deus e o homem ser justo. Em Deus, ser justo tem um carácter substancial porque Deus é a justiça; em Deus, como se afirma no De Hebdomadibus (cfr. p. 50), não há qualquer distinção entre ser e acção - plano em que se inclui o ser justo. No homem esta identificação é impossível: ser justo é um atributo acidental que alguns homens possuem, mas não todos e daí que existam homens justos e outros injustos.

34 Cfr. Utrum Pater, pp. 34-6.

35 DT, p. 24: «Iamne patet quae sit differentia praedicationum? Quod aliae quidem quasi rem monstrant aliae vero quasi circumstantias rei; quodque illa quae ita praedicantur, ut esse aliquid rem ostendant, illa vero ut non esse, sed potius extrin- 
Ou seja, e de acordo com os exemplos que Boécio apresenta exemplos relacionados com o homem mas que nos permitem distinguir de forma clara a predicação intrínseca da predicação extrínseca -, se afirmo que Sócrates é alto e magro, digo algo sobre Sócrates; se declaro que Sócrates está na praça, limito-me a referir algo que lhe é externo e que não nada diz sobre o sujeito em si mesmo: «o predicado [não] se identifica com aquilo de que é predicado». E isto «porque "na praça" não é dito do homem do mesmo modo que "branco" ou "alto" nem, por assim dizer, ele é encerrado ou determinado por alguma propriedade que lhe permita ser descrito em termos de substância [segundo o que é em si mesmo]; este predicado de lugar declara simplesmente a que distância a sua existência está entre as outras coisas, dada a sua posição particular» ${ }^{36}$.

Se esta diferença existe na predicação do homem, em Deus ela será bem mais significativa.

Assim, podemos predicar lugar quer do homem quer de Deus ${ }^{37}$. Por exemplo, podemos dizer que o homem A está na rua; de Deus, por sua vez, já dizemos que ele está em todo o lado, não se querendo com isso dizer que esteja fisicamente presente em todos os lugares mas que todos os lugares lhe são presentes. Da mesma forma, afirmamos que A veio ontem, porque predicamos o homem segundo o tempo, segundo o mutável fluir de um agora que lhe está constantemente a fugir; de Deus dizemos que é sempre: Deus era, é e será segundo a eternidade, num eterno, imóvel e inalterável agora ou, como afirma na Consolação, «o ser eterno abarca e compreende de forma simultânea toda a plenitude da interminável vida $\rangle^{38}$. Isto permite-nos, assim, compreender que ainda que não seja

secus aliquid quodam modo affigant. Illa igitur, quae aliquid esse designant, secundum rem praedicationes vocentur. Quae cum de rebus subiectis dicuntur, vocantur accidentia secundum rem; cum vero de deo qui subiectus non est, secundum substantiam rei praedicatio nuncupatur».

36 DT, p. 20: «Nam ubi vel de homine vel de deo praedicari potest, de homine ut in foro, de deo ut ubique, sed ita ut non quasi ipsa sit res id quod praedicatur de qua dicitur. Non enim ita homo dicitur esse in foro quem ad modum esse albus vel longus nec quasi circumfusus et determinatus proprietate aliqua qua designari secundum se possit, sed tantum quo sit illud aliis informatum rebus per hanc praedicationem ostenditur».

37 Cfr. DT, 20: «De deo vero non ita, nam quod ubique est ita dici videtur non quod in omni sit loco (omnino enim in loco esse non potest) sed quod omnis ei locus adsit ad eum capiendum, cum ipse non suscipiatur in loco; atque ideo nusquam in loco esse dicitur, quoniam ubique est sed non in loco. "Quando" vero eodem praedicatur modo, ut de homine heri venit, de deo semper est. Hic quoque non quasi esse aliquid dicitur illud ipsum de quo hesternus dicitur adventus, sed quid ei secundum tempus accesserit praedicatur. Quod vero de deo dicitur "semper est", unum quidem significat, quasi omni praeterito fuerit, omni quoquo modo sit praesenti est, omni futuro erit».

38 De Consolatione Philosophiae, V, pr. 6, p. 422: «Aeternitas igitur est intermi- 
inconcebível a possibilidade de aplicação das categorias de lugar e tempo a Deus, estas não lhe são, contudo, próprias.

Condição e acção também nada dizem de substancial. Tal como tempo e lugar, «brotam do que está fora da substância, e todos estes predicados se referem a outra coisa que não é a substância» e, tal como nos anteriores, a diferença na sua aplicação a Deus e ao homem é incomensurável: «dizemos sobre um homem: "ele corre, vestido", de Deus "Ele governa, possuindo todas as coisas». Por último, categorias como posição e paixão não podem ser ditas de Deus porque dificilmente até podemos conceber Deus sentado ou em pé ou considerar que um ser imaterial como ele esteja sujeito às paixões e, por exemplo, sofra ${ }^{39}$.

Assim, e em jeito de conclusão, ao procurar mostrar que não é possível a diferença numérica entre as pessoas da Trindade, Boécio oferece-nos, neste tratado, uma análise das estruturas dos seres, que, apesar de se enquadrar numa visão mais alargada desenvolvida nas suas outras obras, não deixa de nos apresentar algumas dificuldades dados os diferentes significados e diferentes implicações (e correspondentes ambiguidades) que os mesmos termos e expressões têm nos diferentes tratados.

$\mathrm{O}$ ser concreto e material, na sua estrutura interna «esse aliquid»e isto significa ser uma coisa ou realidade determinada, ou seja, algo que participa do ser para ser mas que para ser alguma coisa participa de outro princípio que o determine. É um ser composto, que precisa da forma para ser alguma coisa e recebe-a de Deus.

Deus, na sua absoluta simplicidade é perfeita unidade, não existindo nele qualquer distinção entre o seu ser e a sua forma. Ele é a sua própria essência e como Nele forma ou essência nada têm de determinado (nem precisam de qualquer determinação) coincidem com o próprio ser. Deus é, como afirma L. Obertello, «a Forma da forma, a realidade da realidade, aquilo que é maximamente inteligível, maximamente real e maximamente universal $»^{40}$. É objecto máximo a que a razão humana se pode dedicar, e constitui um esforço do homem que procura, tal como refere na Consolação, «elevar o seu espírito à suprema inteligência» ${ }^{41}$ divina, tendo, no entanto, que se debater sempre com os limites da sua própria razão e com a incapacidade de criar um discurso que diga verdadeiramente Deus.

nabilis vitae tota simul et perfecta possessio, quod ex collatione temporalium clarius liquet».

39 Ibidem.

40 L. Obertello, Severino Boezio, p. 651.

41 De Consolatione Philosophiae, V, pr. 5, p. 420. 


\section{RESUMO}

No De Trinitate, Severino Boécio apresenta a divisão tríplice da ciência especulativa e mostra que, apesar das ciências naturais, das ciências matemáticas e da teologia partilharem o mesmo objecto primário - a forma -, distinguem-se pelo modo como o encaram. A teologia considera intelectualmente a verdadeira forma, que se identifica com a substância divina, com o ser mesmo e é fonte do ser. A substância divina é pura forma, forma sem matéria, perfeitamente una e simples e é esta simplicidade que permite afirmar que Deus est id quod est (tomado aqui como significando essência ou forma total). Há, em Deus, uma identidade entre ser e forma que não pode ocorrer nas criaturas. Enquanto seres compostos por matéria e forma, as criaturas devem o seu ser às partes que as compõem e são estas partes conjuntamente (nunca separadamente); a forma é, assim, apenas uma parte da realidade total e, por isso, não há uma identificação entre forma e essência. A forma da criatura é a fonte do seu ser, mas não se identifica com o seu ser; ela deriva da forma que existe à parte da matéria e, como tal, deve ser apenas considerada como imagem da verdadeira forma.

Salvaguardando-se que, neste tratado, Boécio não pretende expressar a diferença entre essência e existência, é contudo possível estabelecer um paralelo entre este escrito e o De Hebdomadibus (um paralelo que exige algum cuidado e adaptação terminológica). Ao afirmar que esse e id quod est são idênticos no ser simples e diversos no ser composto, Boécio volta a enunciar a diferença e oposição ontológica entre simplicidade e composição.

\section{ABSTRACT}

In the De Trinitate, Boethius presents the threefold division of the speculative science and shows that, although natural sciences, mathematics and theology share the same primary object - form - these sciences can be distinguished by the way they face it. Theology, the highest form of human speculation and to which all wise men should devote themselves to, considers intellectually the true and pure form, which Boethius identifies with the divine substance, the being in se and with the source of being. The divine substance is pure form, form without mater and it is this simplicity that allows him to say that God est id quod est (here understood as essence). In God there is an identification between his being and his form that can not occur in creatures. As things composed by matter and form, all creatures owe there being to the parts that compose them and are those parts conjointly; form is, therefore, just a part of their whole reality and thus there can not be an identification between their form and their essence (and consequently, creatures are not id quod sunt). The creature's form derives from the form that is apart from matter and as such it must be distinguished from the true form and designated by image.

In this work we try to show how Boethius uses the ideas of simplicity and composition to enunciate the ontological difference between creatures and their creator. 